JEKPEND Jurnal Ekonomi dan Pendidikan

Volume 1 Nomor 1 Januari 2018. Hal. 45-54

p-ISSN: 2614-2139; e-ISSN: 2614-1973,

Homepage: http://ojs.unm.ac.id/JEKPEND

\title{
PENDEKATAN DATA PANEL METODE COMMON EFFECT TERHADAP FLUKTUASI HARGA DINAMIS JANGKA PANJANG IKAN PELAGIS KECIL (The Panel Data Approaches the Common Effects Method to Long-Term Dynamic Price Fluctuations of Small Pelagic Fish)
}

\author{
Abd. Rahim \\ Ekonomi Pertanian dan Agribisnis, Universitas Negeri Makassar \\ Email : abd.rahim@unm.ac.id
}

\begin{abstract}
The research conducted in South Sulawesi aims to estimate long-term dynamic price fluctuations of small pelagic fish. These objectives use multiple regression analysis method and classical assumption test (multicollinearity and autocorrelation) with Common Effect panel data method approach. Based on the time dimension using time series data from 1991-2014 originating from secondary data. The results of this study found that in general the dynamic long-term price equilibrium of small pelagic fish in South Sulawesi is positively influenced by the price of small pelagic fish itself, the price of small pelagic fish in the past, and the per capita income of the community. Therefore, it is necessary to support the local government or stockholders in order to increase the production of catches to minimize the price fluctuation in the form of increasing the Grosstonase (GT) sea fleet to reach the fishing ground in the further Exclusive Economic Zone (EEE), such as 6-12 miles. This has been referring to the government program since 2010 through the ministry of marine and fisheries, the blue revolution as a grand strategy in implementing the restructuring of the national fleet to increase the production of catches
\end{abstract}

Keywords: Price fluctuation, small pelagic fish, and common effect method

\begin{abstract}
Abstrak. Penelitian yang dilakukan di Sulawesi Selatan bertujuan bertujuan mengestimasi fluktuasi harga dinamis jangka panjang ikan pelagis kecil. Tujuan tersebut menggunakan metode analisis regresi berganda dan pengujian asumsi klasik (multikolinearitas dan autokorelasi) dengan pendekatan metode data panel Common Effect. Berdasarkan dimensi waktu menggunakan data runtun waktu tahun 1991-2014 yang bersumber dari data sekunder. Hasil Penelitian ini menemukan bahwa secara umum fluktuasi harga dinamis jangka Panjang ikan pelagis kecil di Sulawesi Selatan dipengaruhi secara positif oleh harga ikan pelagis kecil sendiri, harga ikan pelagis kecil waktu lalu, dan pendapatan per kapita masyarakat. Untuk itu diperlukan dukungan pemerintah daerah ataupun stockholder dalam rangka meningkatkan produksi tangkapan untuk menekan terjadinya flktuasi harga tersebut berupa peningkatan armada laut berkekuatan Grosstonase (GT) untuk mencapai fishing ground pada Zona Ekonomi Ekslusif (ZEE) yang lebih jauh, seperti 6-12 mil. Hal ini telah mengacu pada program pemerintah sejak tahun 2010 melalui kementerian kelautan dan perikanan, yaitu revolusi biru sebagai grand strategy dalam melaksanakan restrukturisasi armada laut nasional untuk meningkatkan produksi tangkapan.
\end{abstract}

Kata Kunci: Fluktuasi harga, ikan pelagis kecil, dan metode common effect

PENDAHULUAN

Pemasaran ikan pelagis kecil di Indonesia selama ini masih didominasi pada pasar lokal dan antar pulau, tetapi masih terbuka peluang usaha untuk pasar nasional dan ekspor (Rahim, 2010). Pada Indonesia bagian timur jenis 
pelagis kecil seperti ikan layang biru (Decapcerus malalugis) diekspor ke mancanegara sebagai umpan ikan tuna (tuna long line) dan untuk konsumsi masyarakat juga sebagai bahan baku ikan kaleng (Balai Riset Perikanan Laut, 2006) serta sebagai ikan paling melimpah dan sumber makanan predator seperti lumba-lumba dan anjing laut (Nikolsky et. al. 2012)

Nilai komoditas ikan pelagis kecil di Sulawesi Selatan Tahun 2015 seperti layang sebesar Rp 42 milyar, tembang sebesar 23 milyar, dan lemuru sebesar Rp 17 milyar mempunyai nilai ekonomis yang tinggi, dengan produksi tangkapan Layang (3,70 ton) Tembang (2,71 ton), dan lemuru (1,45 ton), jenis ikan pelagis kecil seperti ikan layang diekspor ke Jepang, Taiwan, dan Hongkong (Departeman Perikanan dan Kelautan Sulawesi Selatan, 2015)

Tingginya produksi hasil tangkapan ikan pelagis kecil di Sulawesi Selatan tidak terlepas pula dari peningkatan produksi hasil tangkapan yang mengalami fluktuasi. Pada saat musim penangkapan di perairan Sulawesi Selatan, produksi hasil tangkapan mengalami peningkatan tetapi pada sisi harga menjadi rendah. Sedangkan saat musim paceklik harga menjadi meningkat dengan produksi tangkapan menurun (Rahim, 2012; Rahim dan Hasututi, 2017). Selain itu saat musim penangkapan harga ikan dapat pula menurun saat terjadi bulan terang ataupun terjadi pembelian ikan di tengah laut kemudian didaratkan ke wilayah lain (Rahim, 2010).

Populasi ikan pelagis kecil sangat dipengaruhi oleh iklim (Tommasi et.al 2016), sedangkan fluktuasi yang melimpah karena faktor lingkungan, rezim panen, dan pola reproduksi (Montanez et. al. 2017). Menurut Garcia and Cubillos (2008) lingkungan variabilitas adalah penyebab utama fluktuasi populasi ikan pelagis yang dieksploitasi secara komersial keliling dunia. Meski begitu, tergantung kepadatan Faktor juga dapat mendorong dinamika populasinya.

Adanya kenaikan dan penurunan produksi di setiap saat, maka harga ikan pelagis kecil menjadi tidak stabil atau terjadi fluktuasi harga (Fauzi, 2005) baik di pasar produsen (sentra produksi seperti TPI/tempat pelelangan ikan dan PPI/pusat pendaratan ikan) maupun di pasar konsumen sehingga mempengaruhi pendapatan usaha tangkap nelayan dan tingkat kesejahteraanya di Sulawesi Selatan Indonesia (Rahim, 2010; Rahim, 2012; Rahim dan Hastuti, 2017). Respon harga ikan dan elastisitas permintaan terkait adalah masalah kesejahteraan (Odemero, 2014). Tingkat kesejahteraan yang rendah pada masyarakat nelayan kecil tercermin dari rendahnya pendapatan dan lemahnya posisi tawar pada hampir setiap transaksi kehidupan ekonominya (Thalib, 2001) karena bahwa risiko harga relatif sebagai bagian dari risiko pendapatan perdagangan dan keberagamaan berbagai usaha ikan di tingkat pasar (Dahl and Ogland, 2014).

Fluktuasi harga ikan pelagis kecil disebabkan oleh faktor musim sehingga terjadi ketidakseimbangan antara permintaan dan penawaran ikan laut segar (Rahim and Hastuti, 2017) di Sulawesi Selatan. Pada sisi penawaran, saat musim penangkapan (panen) terjadi over supply, sedangkan musim paceklik (barat dan timur) ataupun musim penangkapan saat terjadi bulan terang produksi menurun (Rahim, 2016). Selain itu fluktuasi harga juga terjadi karena dibeli pedagang di tengah laut dan didaratkan ke wilayah lain, ataupun didaratkan sendiri ke wilayah lain olen nelayan tersebut. sedangkan dari sisi permintaan terjadi peningkatan konsumsi ikan karena adanya faktor selera dan preferensi (Rahim, 2010). Menurut Biscaro and Liviero (2012) aspek pasar ikan pelagis secara khusus terkait dengan penawaran dan permintaan sebagai pembentukan harga

Fluktuasi harga yang tinggi memberikan pula peluang kepada pedagang untuk memanipulasi informasi harga di tingkat nelayan di Sulawesi Selatan (Rahim, 2012). Menurut Irawan (2007) mengemukakan fluktuasi harga bersifat asimetris, artinya jika terjadi peningkatan harga di tingkat konsumen, maka peningkatan harga tersebut tidak dapat diteruskan kepada produsen dengan cepat, begitu pula sebaliknya. Meskipun fluktuasi sering terjadi tetapi sektor usaha tangkap sangatlah propektif, mengingat permintaan yang terus meningkat baik pasar domestik maupun internasional. Jika dikaitkan dengan sistem permintaan inverse, maka variasi harga menjelaskan sebagai fungsi dan variasi kuantitas (Barten and Bettendorf, 1989).

Pada dasarnya tujuan pembangunan perikanan antara lain meningkatkan kesejahteraan nelayan, petani ikan, dan masyarakat pesisir lainnya (Keputusan Menteri Kelautan dan Perikanan No.18/Men/2002) melalui pengembangan kegiatan ekonomi, peningkatan kualitas dan kuantitas sumberdaya manusia, penguatan kelembagaan sosial ekonomi, dan mendayagunakan sumberdaya kelautan dan perikanan secara optimal dan 
berkelanjutan (Keputusan Menteri Kelautan dan Perikanan No.18/Men/2004).

Sektor perikanan tangkap memiliki peran penting dalam ekonomi lokal dan oleh karena itu merupakan risiko terhadap makanan keamanan di tingkat lokal (Ibarra et.al.. 2013), menyediakan lapangan pekerjaan baik pria dan wanita sehingga perdagangan ikan laut mendukung pertumbuhan ekonomi suatu negara (Mohammed and Uraguachi, 2013) serta pembangunan ekonomi dunia akan permintaan di masa di masa depan seiring dengan terkendalanya perikanan global oleh produktivitas dan pengelolaan ekosistemnya (Merino et. al. 2012).

Penelitian tentang fluktuasi harga ikan telah banyak dilakukan di berbagai negara, seperti dilansir oleh Barten and Bettendorf (1989) di Belanda, Mafimisebia (2012), Dahl and Oglend (2014) di Uni Eropa, Jepang, dan Amerika Serikat, Alapan et. al. (2016) di Filipina serta di Indonesia sendiri oleh Rahim (2012) dan Saerang dan Jan (2017). Namun, temuan tersebut belum membahas tentang estimasi atau faktor-faktor yang mempengaruhi fluktusi harga dinamis jangka panjang khususnya ikan pelagis kecil di Provinsi Sulawesi Selatan Indonesia dengan pendekatan ekonomettri data panel metode commont effect.

\section{METODE PENELITIAN}

Dalam penenlitian ini Metode dasar yang digunakan adalah metode eksplanatori. Menurut Singarimbun dan Effendi (1989) penelitian menjelaskan hubungan antar variabel melalui pengujian hipotesis disebut explanatory research (penelitian penjelasan). Explanatory method digunakan untuk menguji dan menganalisis estimasi fluktuasi harga dinamis jangka panjang ikan pelagis kecil di Sulawesi Selatan periode tahun 1991-2014. Macam data dalam penelitian ini berdasarkan dimensi waktu, yaitu data timeseries (runtut waktu) dengan metode panel data common effect. Jenis ikan yang diteliti adalah jenis ikan pelagis kecil, yaitu komoditas layang, tembang, dan lemuru segar.

Pengujian hipotesis faktor-faktor yang mempengaruhi fluktuasi harga dinamis jangka panjang dalam hal ini harga rill ikan laut segar (layang, kembung, dan, lemuru) di Sulawesi Selatan dengan persamaan multiple linear regression dengan model panel data metode common effect yang dipangkatkan sebagai berikut :

$$
\begin{aligned}
& \text { PLyng }_{t}=\beta_{0} \text { PLyng }_{t}^{\beta 1} \text { PLmr }_{t}{ }^{\beta 2} \text { PLyng }_{t-1}{ }^{\beta 3} \text { IPkt }_{t}{ }^{\beta 4} \text { TW }_{t}{ }^{\beta 5} \quad \mu 1 t \\
& \text { PTmbng }_{t}=\beta_{6} \text { PLyng }_{t}{ }^{\beta 7} \text { PLmr }_{t}{ }^{\beta 8} \text { PTmbng }_{t-1}{ }^{\beta 9} \text { IPkt }_{t}{ }^{\beta 10} \mathrm{TW}_{t}{ }^{\beta 11} \quad \mu 2 t \\
& \text { PLmr }_{t}=\beta_{12} \text { PLyng }_{t}{ }^{\beta 13} \text { PTmbng }_{t}{ }^{\beta 14} \text { PLmr }_{t-1}{ }^{\beta 15} \text { IPkt }_{t}{ }^{\beta 16} \mathrm{TW}_{t}{ }^{\beta 17} \quad \mu 3 t
\end{aligned}
$$

Untuk memudahkan perhitungan model persamaan (1), (2), dan (3) maka persamaan metode double log atau logaritme natural (Ln) sebagai berikut:

tersebut diubah menjadi linear berganda dengan

$$
\begin{aligned}
& \text { LnPLyng }_{t}=\operatorname{Ln}_{0}+\beta_{1} \text { LnTmbng }_{t}+\beta_{2} \text { LnLmr }_{t}+\beta_{3} \text { LnPLyng }_{t-1}+\beta_{4} \text { LnIPkt }_{t}+ \\
& \beta_{5} T W_{t}+\mu_{1 t} \\
& \operatorname{LnTmbng}_{t}=\operatorname{Ln}_{6}+\beta_{7} \text { LnPLyng }_{t}+\beta_{8} \operatorname{LnLmr}_{t}+\beta_{9} \operatorname{LnTmbng}_{t-1}+\beta_{10} \text { LnIPkt }_{t}+ \\
& \beta_{11} T W_{t}+\mu_{2 t} \\
& L n L m r_{t}=L n \beta_{12}+\beta_{13} L n P L y n g_{t}+\beta_{14} L_{n T m b n g}+\beta_{15} L n L m r_{t-1}+\beta_{16} \text { LnIPkt }_{t}+ \\
& \beta_{17} T W_{t}+\mu_{3 t}
\end{aligned}
$$

Keterangan :

PLyng $_{t}$ : harga rill layang, tahun ke- $t(\mathrm{Rp})$

Tmbng $_{t} \quad:$ harga rill tembang, tahun ke- $t(\mathrm{Rp})$

$\mathrm{Lmr}_{t} \quad:$ harga rill lemuru, tahun ke- $t(\mathrm{Rp})$

$\beta_{0}, \beta_{6}, \beta_{12} \quad$ : intercept/konstanta

$\beta_{1}, \ldots, \beta_{5} ; \beta_{7}, \ldots, \beta_{11} ; \beta_{13}, \ldots, \beta_{171} \quad$ : koefisien regresi variabel bebas

PLyng $_{t-1} \quad$ : harga rill layang waktu lalu, tahun ke- $t-1$ (Rp)

PTmbng ${ }_{t-1}$ : harga rill tembang waktu lalu, tahun ke- $t(\mathrm{Rp})$

$L m r_{t-1} \quad$ : harga rill kembung waktu lalu, tahun ke- $t$ (Rp) 


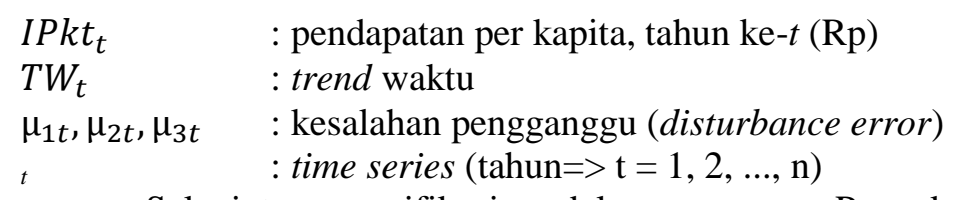

Selanjutnya spesifikasi model persamaan Pengukuran Ketepatan atau kesesuaian model (4), (5), dan (6) dilengkapi dengan pengukuran (goodness of fit) dihitung dengan adjusted $\mathrm{R}^{2}$. ketepatan model (adjusted $\mathrm{R}^{2}$ ), pengujian Menurut Gujarati and Porter (2009) dirumuskan hipotesis ( $\mathrm{F}$ test dan $\mathrm{t}$ test), dan pengujian asumsi sebagai berikut :

klasik (multicollinearity dan autocorrlation).

Adjusted $R^{2}=1-\left(1-R^{2}\right) \frac{(n-1)}{(k-1)}$

di mana :

Adjusted $\mathrm{R}^{2}$ : koefisien determinasi yang disesuaikan

$\mathrm{k}$ : jumlah variabel tidak termasuk intercep

$\mathrm{n} \quad$ : jumlah sampel

Pengujian hipotesis terhadap koefisien menurut Gujarati and Porter (2009) dirumuskan regresi secara bersama-sama digunakan uji-F sebagai berikut :

dengan tingkat kepercayaan tertentu, yang

$$
\begin{aligned}
& F \text { hitung }=\frac{E S S /(k-1)}{R S S /(n-k)} \\
& \text { Ftabel }[(k-1):(n-k) ; \alpha]
\end{aligned}
$$

di mana :

$\alpha \quad$ : tingkat signifikansi atau kesalahan tertentu

Pengujian terhadap koefisien regresi secara individu (parsial) digunakan uji t dengan tingkat kepercayaan tertentu. Menurut Gujarati and Porter (2009) dengan rumus :

$$
\begin{aligned}
& t \text { hitung }=\frac{\beta i}{S \beta i} \\
& t \text { tabel }[(n-k) ; \alpha / 2]
\end{aligned}
$$

di mana:

$\beta_{\mathrm{i}} \quad$ : koefisien regresi ke-i

$\mathrm{S} \beta_{\mathrm{i}} \quad$ : kesalahan standar koefisien regresi ke-i

Selanjutnya uji autokorelasi menggunakan Durbin-Watson test (Gujarati and Porter, 2009) yang dirumuskan sebagai berikut

$$
D W=\frac{\sum\left(e-e_{t-1}\right)^{2}}{\sum e_{t}^{2}}
$$

Keterangan :

e: Nilai Residual

$\mathrm{e}_{\mathrm{t}}$ : nilai residual satu periode sebelumnya

\section{HASIL DAN PEMBAHASAN}

Hasil estimasi analisis dampak fluktuasi harga komoditas substitusi dan pendapatan per kapita terhadap fluktuasi harga dinamis jangka panjang ikan laut segar (layang, tembang, dan lemuru) di Sulawesi Selatan menggunakan pengujian asumsi klasik multikolinearitas dan autokorelasi. Hasil uji multikolinearitas dengan metode Variance Inflaction Factor (VIF) secara umum menunjukkan harga rill kembung, harga rill lemuru, harga rill layang, harga rill kembung 
waktu lalu, harga rill lemuru waktu, harga rill layang waktu lalu, dan dummy perbedaan wilayah (Kabupaten Barru, Jeneponto, dan Sinjai) tidak mengindikasikan terjadi multikolinearitas atau kolinearitas ganda, yaitu nilai VIF lebih kecil dari 10 (Tabel 1).

Jika terjadinya kolinearitas ganda tersebut tidak dilakukan adanya perbaikan atau diabaikan. Menurut Gujarati and Porter (2009) adanya multikolinearitas dapat pula dilakukan tanpa perbaikan karena estimator masih tetap $B L U E$ sehingga tidak memerlukan asumsi tidak adanya korelasi antar variabel independen. Asumsi estimator BLUE adalah selain variabel gangguan tetap konstan (homokedastisitas) juga tidak terdapat hubungan antara variabel gangguan satu dengan variabel gangguan lainnya (non-autokorelasi) sehingga persamaan regrasi menjadi efisien dan konsisten Gujarati and Porter (2009)

Pada uji autokorelasi dengan metode Durbin-Watson (DW) tidak mengindikasikan terjadinya autokorelasi (Tabel 1). Selanjutnya pada pengukuran ketepatan model atau kesesuaian model (goodness of fit) dari nilai adjusted $\mathrm{R}^{2}$ menunjukkan variabel independen pada model fungsi penawaran ikan laut segar berupa kembung, lemuru, dan layang di tingkat konsumen yang disajikan dapat masing-masing menjelaskan sebesar 69,5 persen (layang); 56,6 persen (tembang); dan 36,4 persen (lemuru) dari variasi untuk penawaran ikan laut segar di Sulawesi Selatan sedangkan sisanya masingmaing sebesar 30,5 persen; 43,4 persen; dan 63,6 persen dipengaruhi oleh variabel lain yang tidak dimasukkan dalam model.

Nilai intersep/ konstanta sebesar $-1,657$ pada fungsi fluktuasi harga dinamis jangka panjang ikan layang di Sulawesi Selatan menunjukkan bahwa tanpa variabel independen (Harga rill ikan tembang, Harga rill ikan lemuru, Harga rill ikan layang waktu lalu, pendapatan per kapita, dan Trend waktu) maka nilai intersep/ konstantanya turun masing-masing sebesar 1,657. Selanjutnya hasil uji-F masing-masing sebesar 26,503 (layang); 15,624 (tembang); dan 7,418 (lemuru) menunjukkan bahwa dampak fluktuasi harga komoditas substitusi dan pendapatan per kapita terhadap fluktuasi harga dinamis jangka panjang ikan laut segar (layang, tembang, dan lemuru) di Sulawesi Selatan secara signifikan berpengaruh simultan pada tingkat kesalahan 1 persen atau tingkat kepercayaan 99 persen (Tabel 1).
Selanjutnya pengaruh secara individu berdasarkan uji-t dari masing-masing variabel independen terhadap fluktuasi harga dinamis jangka panjang ikan pelagis kecil di Sulawesi Selatan menggunakan nilai koefisien regresi. Pada jenis ikan layang, yaitu variabel harga rill ikan lemuru, harga rill ikan layang waktu lalu, dan pendapatan per kapita berpengaruh signifikan terhadap fluktuasi harga dinamis jangka panjang ikan layang segar di Sulawesi Selatan, sedangkan harga rill ikan tembang, harga rill ikan tembang waktu lalu, harga rill ikan lemuru waktu lalu, dan pendapatan per kapita, dan trend waktu tidak berpengaruh signifikan. Hasil ini tidak sejalan dengan temuan Alapan et. al. (2016) bahwa harga ikan dan kualitas ikan mempengaruhi harga pasar ikan di di Bagian Utara Surigao Del Sur, Filipina. 
Tabel 1. Estimasi Fluktuasi Harga Dinamis Jangka Panjang Ikan Pelagis Kecil di Sulawesi Selatan, Indonesia

\begin{tabular}{|c|c|c|c|c|c|c|c|c|c|c|}
\hline \multirow[b]{2}{*}{ Variabel Independen } & \multirow[b]{2}{*}{ T.H } & \multicolumn{3}{|c|}{ Layang } & \multicolumn{3}{|c|}{ Tembang } & \multicolumn{3}{|c|}{ Lemuru } \\
\hline & & $\begin{array}{l}\text { Koefisien } \\
(\beta)\end{array}$ & $\begin{array}{c}\mathrm{t} \\
\text { hitung }\end{array}$ & VIF & $\begin{array}{l}\text { Koefisien } \\
(\beta)\end{array}$ & $\begin{array}{c}\mathrm{t} \\
\text { hitung }\end{array}$ & VIF & $\begin{array}{l}\text { Koefisien } \\
(\beta)\end{array}$ & $\begin{array}{c}\mathrm{t} \\
\text { hitung }\end{array}$ & VIF \\
\hline Harga rill ikan layang & - & - & - & - & $0,131^{\mathrm{ns}}$ & 0,630 & 2,906 & $0,564 * * *$ & 3,257 & 2,368 \\
\hline Harga rill ikan tembang & - & $-0,010^{\mathrm{ns}}$ & $-0,123$ & 2,134 & - & - & - & $0,155^{\mathrm{ns}}$ & 1,327 & 2,065 \\
\hline Harga rill ikan lemuru & - & $0,201 * *$ & 2,582 & 1,241 & $0,094^{\mathrm{ns}}$ & 0,664 & 1,521 & - & - & - \\
\hline Harga rill ikan layang waktu lalu & + & $0,424 * * *$ & 3,649 & 2,727 & - & - & - & - & - & - \\
\hline Harga rill ikan tembang waktu lalu & + & & - & - & $0,523 * * *$ & 3,150 & 2,535 & - & - & - \\
\hline Harga rill ikan lemuru waktu lalu & + & & - & - & & & - & $0,435 * * *$ & 3,539 & 1,321 \\
\hline Pendapatan per kapita & + & $0,224 * * *$ & 2,971 & 2,244 & $0,044^{\mathrm{ns}}$ & 0,340 & 2,449 & $-0,331 * * *$ & $-2,962$ & 2,112 \\
\hline Trend waktu & + & $0,005^{\mathrm{ns}}$ & 1,349 & 1,863 & $0,015 * * *$ & 2,306 & 2,292 & $-0,006$ & $-1,174$ & 1,885 \\
\hline Konstanta/ intersep & & & & $1,657 *$ & & &, $036 * *$ & & & $335 * * *$ \\
\hline F hitung & & & & 26,503 & & & 15,624 & & & 7,418 \\
\hline Adjusted $\mathrm{R}^{2}$ & & & & 0,695 & & & 0,566 & & & 0,364 \\
\hline Durbin Watson (DW) & & & & 2,417 & & & 2,486 & & & 2,381 \\
\hline $\mathrm{n}$ & & & & 60 & & & 60 & & & 60 \\
\hline $\mathrm{n}$ hasil regresi & & & & 57 & & & 57 & & & 57 \\
\hline
\end{tabular}

Sumber : Hastuti et. al (2015)

Keterangan : $* * *=$ Signifikan pada tingkat kesalahan 1 persen $(0,01)$, atau tingkat kepercayaan 99 persen

$* *$ = Signifikan pada tingkat kesalahan 5 persen $(0,05)$, atau tingkat kepercayaan 95 persen

${ }^{\mathrm{ns}}=$ Tidak signifikan

T.H = Tanda Harapan

Multicollinearity test $=$ jika nilai VIF lebih kecil dari 10 maka tidak terdapat multikolinearitas , sebaliknya

jika nilai VIF lebih besar dari 10 maka terdapat multikolinearitas

Autocorrelation test $=\mathrm{DW}_{\text {tabel }}=$ Auto $(+) \Rightarrow \mathrm{dl}=1,253 \mathrm{dan} \mathrm{du}=1,909$;

Auto $(-)=>4-\mathrm{du}=2,091$ dan $4-\mathrm{dl}=2,747$ 
Lain halnya fluktuasi harga dinamis jangka panjang ikan tembang segar di Sulawesi Selatan dipengaruhi secara signifikan oleh harga rill ikan tembang waktu lalu dan trend waktu, sedangkan harga rill ikan layang, harga rill ikan lemuru dan pendapatan per kapita tidak berpengaruh signifikan. Selanjutnya fluktuasi harga dinamis jangka panjang ikan lemuru segar di Sulawesi Selatan dipengaruhi secara signifikan oleh harga rill ikan layang, harga rill ikan lemuru waktu lalu, dan pendapatan per kapita, sedangkan harga rill ikan tembang dan trend waktu.

Hasil yang tidak sesuai tanda harapan yaitu negatif (Tabel 1), menunjukkan bahwa perubahan harga secara positif terhadap harga ikan pelagis kecil, konsumsi ikan di Sulawesi Selatan cenderung tidak mengalami perubahan karena ikan laut merupakan konsumsi utama masyarakat Sulawesi Selatan. Hasil ini sejalan dengan temuan Saerang dan Jan (2017) bahwa perubahan harga ikan mujair, ikan, telur, ayam dan curah hujan, masyarakat Sulawesi Utara tetap mengkonsumsi ikan laut. Namun tidak sejalan dengan temuan Lebiedzinska et. al. (2006) bahwa Konsmsi mahasiswa Medical University of Gdansk (Poland) bahwa harga sebagai faktor yang menentukan pilihannya dibandingkan nilai gizi dan dampak kesehatan.

Selanjutnya pengaruh positif dapat terjadi jika pendapatan per kapita masyarakat meningkat maka harga layang di Sulawesi Selatan meningkat akibat dari peningkatan permintaan ikan tersebut. Hal ini sejalan dengan penelitian Wahyuningsih (1998) dan Rahim (2010) pendapatan per kapita berpengaruh positif terhadap fluktuasi harga rill ikan tongkol di tingkat produsen Kabupaten Gunung Kidul. Lain halnya pengaruh negatif, yaitu jika pendapatan per kapita meningkat maka fluktuasi harga rill lemuru menurun. Menurut Boerma (1968) dan Rahim (2012) salah satu faktor yang mempunyai pengaruh penting dalam konsumsi hasil perikanan adalah pendapatan.

Pada hakikatnya keadaan dari adanya kenaikan dari peningkatan pendapatan per kapita masyarakat Sulawesi Selatan tidak menimbulkan perubahan permintaan terhadap komoditas lain (selain ikan laut segar) baik jangka pendek seperti faktor selera dan preferensi maupun jangka panjang seperti faktor pendapatan dan jumlah penduduk. Menurut Hanafiah dan Saefuddin (1986) dan Rahim (2010) mengemukakan adanya perubahan tingkat pendapatan per kapita akan mempengaruhi naik-turunnya permintaan hasil perikanan tangkap dalam jangka panjang.

Lain halnya fluktuasi rill harga tembang tidak dipengaruhi oleh pendapatan per kapita. Hal ini dapat terjadi jika dengan adanya perubahan pendapatan per kapita masyarakat memilih jenis lainnya (layang dan lemuru) walaupun harga rill layang dan tembang lebih murah karena faktor selera dan preferensi. Tiap-tiap konsumen mempunyai preferensi yang berbeda-beda terhadap produk. Preferensi tersebut meliputi ras, agama, penduduk kota atau desa, pendidikan, dan pergaulan (Boerma,1968; Rahim, 2012).

\section{SIMPULAN DAN SARAN}

Penelitian ini menemukan bahwa secara umum fluktuasi harga dinamis jangka panjang di Sulawesi Selatan dipengaruhi secara positif oleh harga ikan laut segar, harga ikan laut segar waktu lalu, dan pendapatan per kapita masyrakat. Pengaruh positif dan negatif antar harga sesama jenis ikan laut segar di Sulawesi Selatan akibat ketidakseimbangan antara permintaan dan penawaran, serta pengaruh perubahan pendapatan per kapita terhadap harga ikan laut segar tidak mengakibatkan turunnya permintaan masyarakat di Kabupaten Barru akan ikan laut segar, baik saat musim penangkapan maupun paceklik. Untuk itu diperlukan dukungan pemerintah daerah ataupun stockholder dalam rangka 
meningkatkan produksi tangkapan untuk untuk menekan terjadinya flktuasi harga tersebut berupa peningkatan armada laut berkekuatan Grosstonase (GT) untuk mencapai fishing ground pada Zona Ekonomi Ekslusif (ZEE) yang lebih jauh, seperti 6 s.d. 12 mil. Hal ini telah mengacu pada program pemerintah tahun 2010 melalui kementerian kelautan dan perikanan, yaitu revolusi biru sebagai grand strategy dalam melaksanakan restrukturisasi armada laut nasional untuk meningkatkan produksi tangkapan.

\section{DAFTAR PUSTAKA}

Alapan, M.P., E.L.I. Arpilleda, K.J.R. Altizo, G.K.R. Frias, \& J.R. Ravelo. 2016. Factors Affecting the Market Price of Fish in the Northern Part of Surigao Del Sur, Philippines. Journal of Environment and Ecology. 7(2):34-41

Balai Riset Perikanan Laut, 2006, Malalugis, Ikan Layang Biru berpotensi Ekspor, Direktorat Jenderal Kelautan dan Perikanan Republik Indonesia, Jakarta

Barten, A.P., And L.J. Bettendorf. 1989. Price Formation of Fish (An Application Of An Inverse Demand System). European Economic Review. 33: 1509-1525.

Biscaro, Q., and A. Liviero. 2012. A Price Analysis and Management Model for Adriatic Small Pelagic fish. New Mediterranean Journal of Economics. 11(1):19-26.

Boerma, A.H., 1968, Fisheries in Food Economy, Basic Study, Food Agricultural and Organization, No.19 Rome

Dahl, R.E., and A. Oglend. 2014. Fish Price Volatility. Marine Resource Economics. 29(4) 305-322

Dinas Kelautan dan Perikanan Sulawesi Selatan. 2015. Statistik Perikanan Tangkap Sulawesi Selatan. Dinas Kelautan dan Perikanan.
Abd. Rahim, Pendekatan Data Panel... $\mid 52$

Fauzi, A., 2005, Kebijakan Perikanan dan Kelautan (Isu, Sintesis, dan Gagasan), Gramedia Pustaka Utama, Jakarta

Garcia, M.P., and L. A. Cubillos. 2008. Population Dynamics of Two Small Pelagic Fish in The Central-South Area off Chile: Delayed DensityDependence and Biological Interaction. Environmental Biology Fishes. 82(2):111-122

Gujarati, D.N., Porter D.C. 2009. Basic Econometrics. $5^{\text {th }}$ edition.McGrawHill. American

Hastuti, D.R.D., A. Rahim, M.I.Maruf,. 2015. Dampak Fluktuasi Harga Komoditas Substitusi dan Pendapatan Per Kapita Terhadap Fluktuasi Harga Dinamis Jangka Panjang Ikan Laut Segar di Sulawesi Selatan. Penelitian PNBP Fakultas Ekonomi Universitas Negeri Makassar. Makassar

Ibarra, A.A., A. S. Vargas, and B. M. Lopez. 2013. Economic impacts of climate change on two Mexican coastal fisheries: implications for food security. Journal of Economic Literature Classification. pp1-32

Irawan, B., 2007, Fluktuasi Harga dan Transmisi Harga serta Margin Pemasaran Sayuran Buah, Jurnal Analisis Kebijakan Pertanian. 5(4):45-57

Keputusan Menteri Kelautan dan Perikanan Nomor 18/Men/2002, Tentang Rencana Strategis Pembangunan Kelautan Perikanan Tahun 20022004, Jakarta

Lebiedzinska A., A. Kostrzewa, J. Ryoekiewicz, R. Bikowski, P. Szefer. 2006. Preferences, Consumption And Choice Factors Of Fish And Seafood Among University Students. Polish Journal of Food and Nutrition Sciences. 15/56(1):91-96 
Abd. Rahim, Pendekatan Data Panel... | 53

Mafimisebia, T.E. 2012. Spatial Equilibrium, Market Integration and Price Exogeneity in Dry Fish Marketing in Nigeria: A Vector Auto-Regressive (VAR) Approach. Journal of Economics, Finance and Administrative Science. 17(33):3137

Merino, G., M. Barange, J. L. Blanchard, J. Harle, R. Holmes, I. Allen, E. H. Allison, M.C. Badjeck, N. K. Dulvy, J. Holt, S. Jennings, C. Mullon, L. D. Rodwell. 2012. Can Marine Fisheries And Aquaculture Meet Fish Demand From A Growing Human Population In A Changing Climate? Global Environmental Change. Pp1-12

Mohammed, E.Y., and Z.B. Uraguchi. 2013. Impacts Of Climate Change On Fisheries:Implications For Food Security In Sub-Saharan Africa. International Global Food Security. Pp113-132

Montanez, J.A.D.A., S. Salas, and G. G.Cortes. 2017. Dealing with Dynamics and Uncertainty of Small Pelagic Fisheries: Bioeconomic Analysis of Manager's Responses to Alternative Management Strategies. Revista De Biología Marina Y Oceanografía. 52(1):51-65

Nikolsky, V., G. Shulman, A. Shchepkina, T. Yuneva, L. Bat, Y. Kaya, A. Kidey, K. Seyhan. 2012. Assessment of Food Supply of Small Pelagic Fish in the Black Sea Based on Their Lipid Content. Turkish Journal of Fisheries and Aquatic Sciences. 12: 429-434

Odemero, A.F. 2014. Price Transmission and Households Demand Elasticity for Frozen Fish Under Fuel Subsidy Reform in Delta State, Nigeria. International Journal of Food and Agricultural Economics. 1(1):119127
Rahim, A. 2010. Analisis Harga Ikan Laut Segar dan Pendapatan Usaha Tangkap Nelayan di Sulawesi Selatan. Disertasi. Program Doktor Ekonomika Pertanian Universitas Gadjah Mada Jogjakarta

Rahim, A., 2012, Model Ekonometri Fluktuasi Harga Ikan Laut Segar di Pasar Produsen dan Konsumen. Jurnal Ekonomi Pembangunan Dan Pertanian. 1(1):1-14

Rahim, A. 2012. Model Ekonometrika Perikanan Tangkap. Badan Penerbit Universitas Negeri Makassar.

Rahim, A., 2016, Estimasi Fluktuasi Harga Ikan Laut Segar Dengan Metode Fixed Effect. Jurnal Ekonomi Pembangunan Dan Pertanian. 2(2):125-140

Rahim, A. 2016. Respon Penawaran Ikan Laut Segar. Jurnal Scientific Pinisi. 2(2): 79-85

Rahim, A., and D.R.D. Hastuti. 2017. Demand Estimation of Fresh Sea Fish with Panel Data Model" Proceeding International Conference on Education, Science, Art and Technology (ICESAT). 1(1):278-287

Saerang, I.S., and A.H. Jan. 2017. Price Fluctuations Analysis of Sea Fish Consumption in North Sulawesi. Journal of Research in Business, Economics and Management. 8(6):1549-1555

Singarimbun, M., dan S. Effendi, 1989, Metode Penelitian Survei, Lembaga Penelitian Pendidikan dan Penerangan Ekonomi Sosial (LP3ES), Jakarta

Tommasi, D, C. A. Stock, K. Pegion, G. A. Vecchi, R. D. Methot, M. A. Alexander, and D. M. Checkley. 2016. Improved Management of Small Pelagic Fisheries Through Seasonal Climate Prediction. Ecological Applications, 0(0): 1-10 
Thalib, J., 2001, Minimisasi Risiko Pendapatan Nelayan Kecil melalui Pengembangan Industri Tepung Ikan di Sulawesi Selatan, Analisis (Jurnal Ilmiah Pascasarjana Unhas), Makasaar, www.pascaunhas.net, diakses 20 Juli 2016 